(2) Open Access Full Text Article

\title{
Spontaneous resolution of foveal detachment in dome-shaped macula observed by spectral domain optical coherence tomography
}

This article was published in the following Dove Press journal:

Clinical Ophthalmology

19 December 2013

Number of times this article has been viewed

\section{Nazuki Tamura \\ Tsutomu Sakai \\ Hiroshi Tsuneoka}

Department of Ophthalmology, Jikei University School of Medicine, Tokyo, Japan
Correspondence: Tsutomu Sakai Department of Ophthalmology, Jikei University School of Medicine, 3-25-8 Nishishinbashi, Minato-ku, Tokyo I05-846I, Japan

Tel +8 I 334 33 I I I I ext 358 I

Fax +8I 334331936

Email tstmski@jikei.ac.jp
Abstract: Dome-shaped macula (DSM) was described by Gaucher et al as a convex protrusion of macula within a staphyloma in highly myopic eyes that causes visual impairment associated with serous foveal detachment (SFD). We describe a patient with spontaneous resolution of SFD in DSM documented by serial spectral domain optical coherence tomography (SD-OCT). A 28-year-old female Japanese patient presented with blurred vision in both eyes. Upon examination, her best-corrected visual acuity was 1.2 with -8.0 sphere and 0.5 with -8.0 sphere in the right and left eyes, respectively. SD-OCT in both eyes showed an anterior bulge of the macula with SFD. The diagnosis of DSM with SFD was made on the basis of characteristic findings. Three months later, the patient achieved spontaneous resolution of SFD without treatment. One month later, there was an occurrence of SFD in the right eye, but the SFD had disappeared in 1 month. In our case, her visual impairment was proven to be a consequence of SFD in relation to DSM. SD-OCT was useful for the detection and follow-up of SFD in DSM.

Keywords: dome-shaped macula, serial spectral domain optical coherence tomography, resolution

\section{Introduction}

Dome-shaped macula (DSM) was first described in 2008 using optical coherence tomography (OCT) by Gaucher et al. ${ }^{1}$ This condition involves a protrusion of the macula within a staphyloma in highly myopic eyes, which causes visual impairment associated with serous foveal detachment (SFD). ${ }^{2}$ Although the pathogenesis of DSM remains unclear, Imamura et $\mathrm{al}^{3}$ showed that DSM was associated with a relative localized thickness variation of the sclera under the macula. Recently, Caillaux et $\mathrm{al}^{4}$ demonstrated that chronic SFD was associated with decreased vision and was more common when the macular bulge was highly elevated. Therefore, DSM with SFD may be involved in more severe DSM forms. Here, we describe a patient with spontaneous resolution of SFD in DSM documented by serial spectral domain OCT (SD-OCT).

\section{Case report}

A 28-year-old female Japanese patient with no previous history of ocular disease was referred to our hospital 14 days after complaining of blurred vision in both eyes. She reported that she had flu-like symptoms 7 days before the initial visit. Upon initial examination, her best corrected visual acuity (BCVA) was 1.2 with -8.0 sphere and 0.5 with -8.0 sphere in the right and left eyes, respectively. No significant findings were observed in the anterior segment or vitreous of either eye. Funduscopy showed a mild staphyloma with some pigmentary changes in the fovea in both eyes 

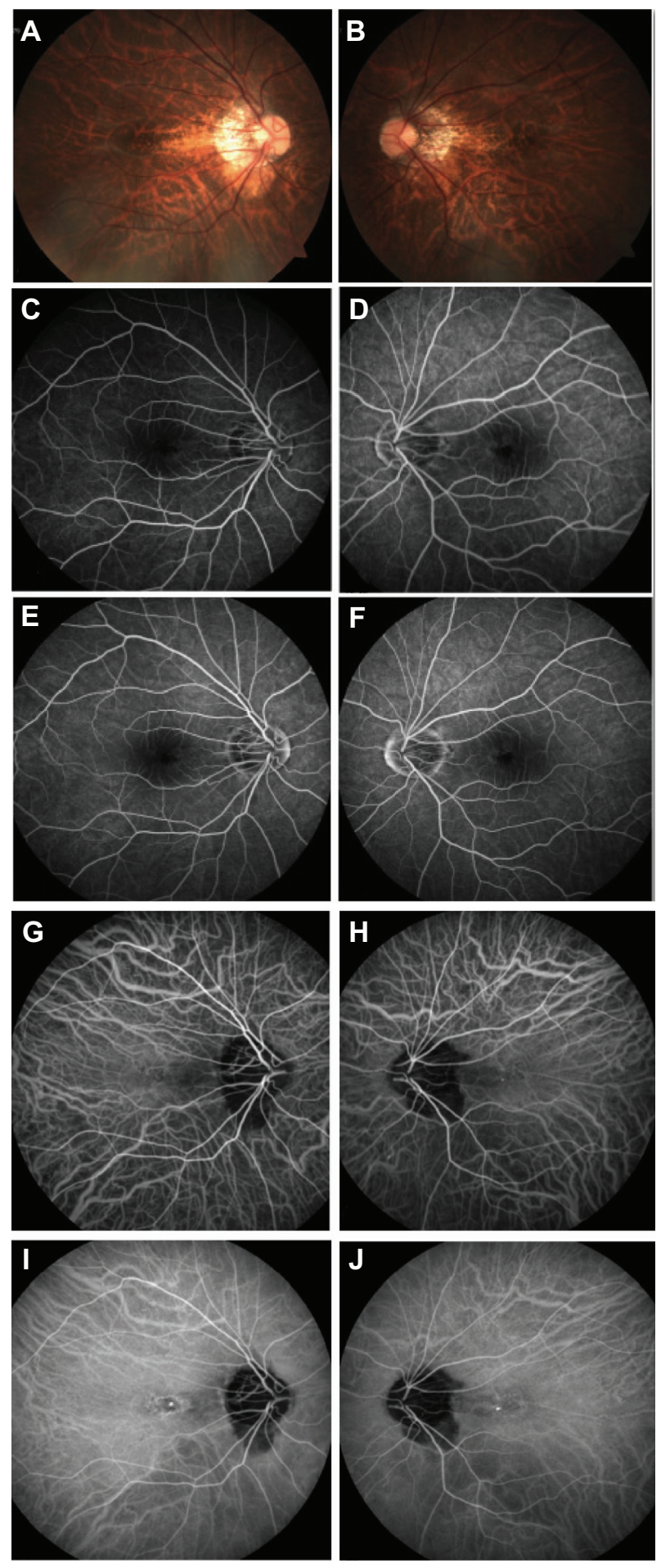

Figure I Fundus photography, fluorescein angiography, and indocyanine green angiography.

Notes: (A and B) Fundus photograph showing a mild staphyloma with some pigmentary changes in the (A) right and (B) left fovea. (C-F) Fluorescein angiography showing hyperfluorescence in the ( $\mathbf{C}$ and $\mathbf{E})$ right and $(\mathbf{D}$ and $\mathbf{F})$ left fovea resulting from a retinal pigment epithelium defect. ( $\mathbf{C}$ and $\mathbf{D})$ Early- or (E and $\mathbf{F})$ late-phase fluorescein angiography image showing no leakage point. (G-J) Indocyanine green angiography showing mild hypofluorescence in the area of retinal pigment epithelium atrophy in the ( $\mathbf{G}$ and $\mathbf{I}$ ) right and $(\mathbf{H}$ and $\mathbf{J}$ ) left fovea. ( $\mathbf{G}$ and $\mathbf{H}$ ) Early- or ( $\mathbf{I}$ and J) late-phase indocyanine green angiography image showing no choroidal vascular hyperpermeability.
(Figure 1A and 1B). Fluorescein angiography (HRA2; Heidelberg Engineering GmbH, Heidelberg, Germany) showed hyperfluorescence in the fovea in both eyes resulting from a retinal pigment epithelium defect, but there was no leakage point (Figure 1C and 1D). Indocyanine green angiography (HRA2; Heidelberg Engineering) in both eyes revealed punctuate hyperfluorescence in the fovea with no vascular hyperpermeability (Figure 1E and 1F). SD-OCT (CIRRUS HD-OCT; Carl Zeiss Meditec AG, Jena, Germany) in both eyes showed an anterior bulge of the macula with SFD in the horizontal scan (Figure 2A and 2B). The diagnosis of DSM with SFD was made on the basis of characteristic findings from previous studies. ${ }^{1-3}$ No treatment was initiated.

Three months later, SFD seen at the initial visit disappeared on SD-OCT (Figure $2 \mathrm{C}$ and $2 \mathrm{~F}$ ), and the patient's BCVA was 1.2 and 1.0 in the right and left eyes, respectively. Her symptoms had also subjectively improved. One month later, there was an occurrence of SFD in the right eye (Figure $2 \mathrm{G}$ and $2 \mathrm{H}$ ), although subjective visual worsening was not reported. The left eye remained unaffected. One month later, the SFD had disappeared (Figure 2I and 2J), and the patient's BCVA was 0.9 in the right eye.

\section{Discussion}

To our knowledge, this is the first report of the spontaneous resolution of SFD in DSM, based on a MEDLINE ${ }^{\circledR}$ (US National Library of Medicine, Bethesda, MD, USA) search of the English literature available on this subject. In this case, SD-OCT provided a definite diagnosis of DSM with SFD and permitted documentation of the spontaneous resolution of SFD in DSM. Similar spontaneous resolution was noted in cases with idiopathic central serous chorioretinopathy, and angiography and OCT enable differentiation from idiopathic central serous chorioretinopathy. In particular, punctuate hyperfluorescence with no vascular hyperpermeability on indocyanine green angiography, and an abnormal convex profile with no choroidal thickening on SD-OCT, may be important findings in DSM with SFD. ${ }^{1}$

Regarding the pathophysiology of DSM with SFD, Imamura et $\mathrm{al}^{3}$ suggested that severe obstruction in the outflow of choroidal fluid might be associated with the characteristic findings of DSM, while Byeon and $\mathrm{Chu}^{5}$ proposed that compressive changes of the choroid and choriocapillaris, as well as the resultant secondary retinal pigment epithelium changes, may be involved in the pathophysiology of DSM. Additional imaging analyses may reveal the details of the pathophysiology of DSM with SFD. 

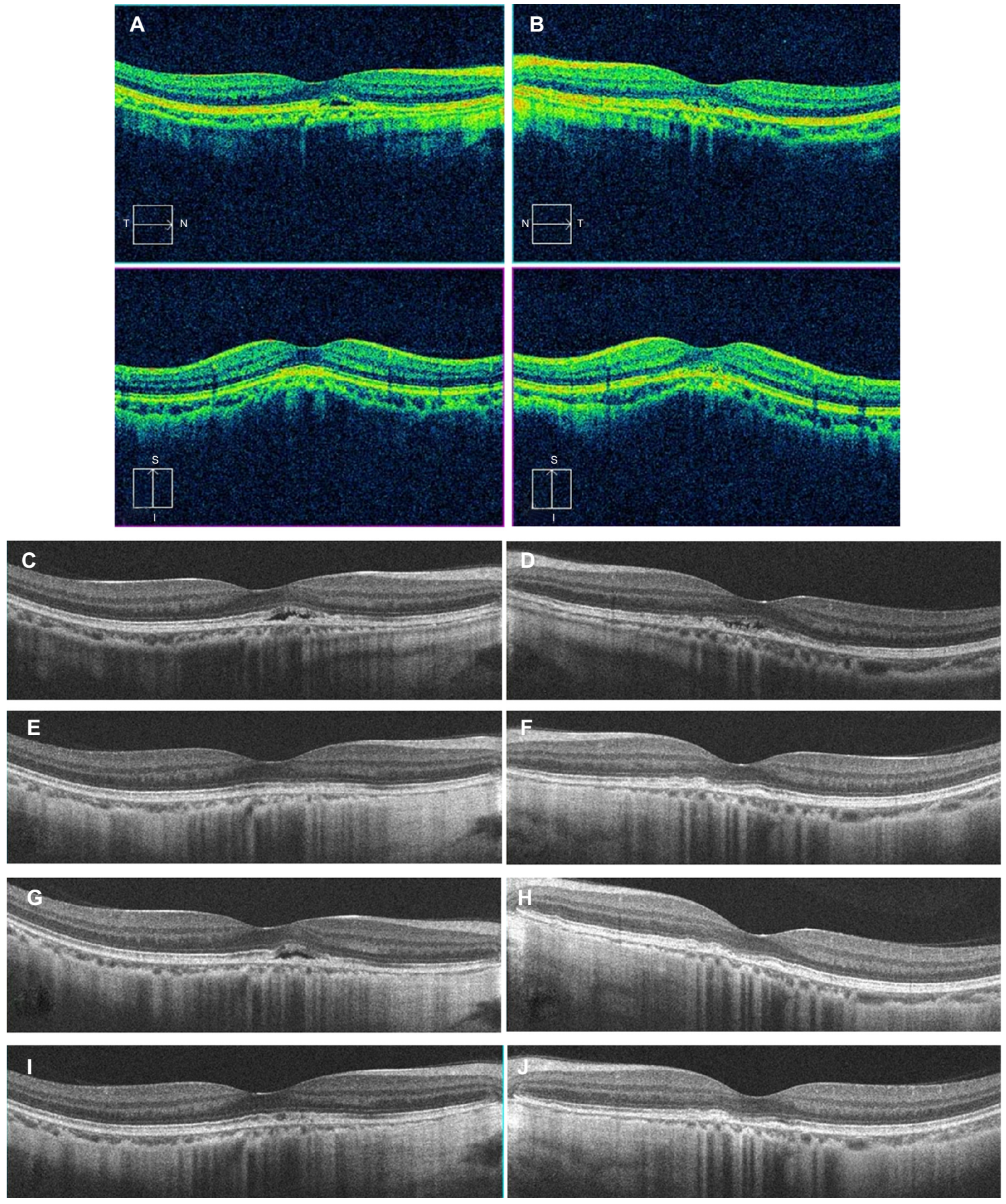

Figure 2 Spectral domain optical coherence tomography in both eyes at initial and follow-up visits for dome-shaped macula with serous foveal detachment. Notes: Spectral domain-optical coherence tomography in both eyes at (A and $\mathbf{B}$ ) initial and (C-J) follow-up visits for dome-shaped macula with serous foveal detachment. (A and B) Cross-line spectral domain optical coherence tomography scan showing the anterior bulge of the macula involving the retina, retinal pigment epithelium, and choroid. Horizontal optical coherence tomography scan showing a shallow retinal detachment in the fovea at the initial visit. (C-J) Follow-up horizontal optical coherence tomography scan showing fluctuation and resolution of the retinal detachment in the right and left eyes, respectively.

The SD-OCT images in our patient clearly showed shallow SFD in the parafovea and foveal center in the right and left eyes, respectively. In this case, a conservative observation was used, although left visual acuity was poor. Use of antivascular endothelial growth factor therapy, photodynamic therapy, and focal laser treatment have been described in other cases, but none of these approaches were effective. ${ }^{4}$ This suggests that choroidal neovascularization and choroidal vascular hyperpermeability are not associated with the pathophysiology of DSM with SFD. 
In conclusion, the patient in this case had DSM with SFD, which showed spontaneous recovery without treatment. This case illustrates the utility of SD-OCT for the detection and follow-up of DSM with SFD.

\section{Disclosure}

The authors did not receive financial support for this study. The authors report no conflicts of interest in this work.

\section{References}

1. Gaucher D, Erginay A, Leleire-Collet A, et al. Dome-shaped macula in eyes with myopic posterior staphyloma. Am J Ophthalmol. 2008; 145(5):909-914.
2. Pardo-López D, Gallego-Pinazo R, Mateo C, et al. Serous macular detachment associated with dome-shaped macula and tilted disc. Case Rep Ophthalmol. 2011;2(1):111-115.

3. Imamura Y, Iida T, Maruko I, Zweifel SA, Spaide RF. Enhanced depth imaging optical coherence tomography of the sclera in domeshaped macula. Am J Ophthalmol. 2011;151(2):297-302.

4. Caillaux V, Gaucher D, Gualino V, Massin P, Tadayoni R, Gaudric A. Morphologic characterization of dome-shaped macula in myopic eyes with serous macular detachment. Am J Ophthalmol. 2013;156(5): 987-967. e1.

5. Byeon SH, Chu YK. Dome-shaped macula. Am J Ophthalmol. 2011; 151(6):1101; author reply 1101-1102.
Clinical Ophthalmology

\section{Publish your work in this journal}

Clinical Ophthalmology is an international, peer-reviewed journal covering all subspecialties within ophthalmology. Key topics include: Optometry; Visual science; Pharmacology and drug therapy in eye diseases; Basic Sciences; Primary and Secondary eye care; Patient Safety and Quality of Care Improvements. This journal is indexed on

\section{Dovepress}

PubMed Central and CAS, and is the official journal of The Society of Clinical Ophthalmology (SCO). The manuscript management system is completely online and includes a very quick and fair peer-review system, which is all easy to use. Visit http://www.dovepress.com/ testimonials.php to read real quotes from published authors. 